\title{
Aerobic and anaerobic microbiology of infections after trauma in children
}

\author{
Itzhak Brook
}

\begin{abstract}
Objective-To review the recovery of aerobic and anaerobic bacteria from infections after trauma in children over a 20 year period.

Methods-Only specimens that were studied for both aerobic and anaerobic bacteria were included in the analysis. They were collected from seven separate centres in which the microbiology laboratories only accepted specimens that were properly collected without contamination and were submitted in appropriate transport media. Anaerobes and aerobic bacteria were cultured and identified using standard techniques. Clinical records were reviewed to identify post-trauma patients.

Results-From 1974 to 1994, 175 specimens obtained from 166 children with trauma showed bacterial growth. The trauma included blunt trauma (71), lacerations (48), bites (42), and open fractures (5). Anaerobic bacteria only were isolated in 38 specimens $(22 \%)$, aerobic bacteria only in 51 (29\%), and mixed aerobic-anaerobic flora in 86 (49\%); 363 anaerobic (2.1/specimen) and 158 aerobic or facultative isolates ( $0.9 /$ specimen) were recovered. The predominant anaerobic bacteria included Peptostreptococcus spp (115 isolates), Prevotella spp (68), Fusobacterium spp (52), B fragilis group (42), and Clostridium spp (21). The predominant aerobic bacteria included Staph aureus (51), E coli (13), Ps aeruginosa
\end{abstract}

(12), Str pyogenes (11) and Klebsiella pneumoniae (9). Principal infections were: abscesses (52), bacteraemia (3), pulmonary infections (30, including aspiration pneumonia, tracheostomy associated pneumonia, empyema, and ventilator associated pneumonia), wounds ( 36 , including cellulitis, post-traumatic wounds, decubitus ulcers, myositis, gastrostomy and tracheostomy site wounds, and fasciitis), bites (42, including 23 animal and 19 human), peritonitis (4), osteomyelitis (5), and sinusitis (3). Staph aureus and Str pyogenes were isolated at all sites. However, organisms of the oropharyngeal flora predominated in infections that originated from head and neck wounds and abscesses, and bites, and those from the gastrointestinal tract predominated in infections that originated from peritonitis, abdominal abscesses, and decubitus ulcers.

Conclusions-Many infections that follow trauma in children involve multiple organisms.

( $($ Accid Emerg Med 1998;15:162-167)

Keywords: trauma; children; infection, anaerobic bacteria

Trauma is often associated with the development of local or systemic infection. ${ }^{1}$ Trauma can induce these infections by causing internal injuries which can expose the host to external or endogenous pathogens. Infections can also occur in traumatised patients as a result of

solated from 175 specimens obtained from 166 children with post-trauma infection

\begin{tabular}{|c|c|c|c|c|c|c|c|c|c|c|c|c|c|c|}
\hline & $\begin{array}{l}\text { No of } \\
\text { specimens }\end{array}$ & $\begin{array}{l}\text { Pepto- } \\
\text { streptococcus } \\
s p p\end{array}$ & $\begin{array}{l}\text { Microaero- } \\
\text { philic } \\
\text { strep }\end{array}$ & $\begin{array}{l}P \\
\text { acnes }\end{array}$ & $\begin{array}{l}\text { Veillonella } \\
s p\end{array}$ & $\begin{array}{l}\text { Clostridium } \\
\text { spp }\end{array}$ & $\begin{array}{l}\text { Bifido- } \\
\text { bacteria } \\
s p\end{array}$ & $\begin{array}{l}\text { Eubacteria } \\
\text { spp }\end{array}$ & $\begin{array}{l}\text { Lacto- } \\
\text { bacillus } \\
\text { spp }\end{array}$ & $\begin{array}{l}\text { Fuso- } \\
\text { bacterium } \\
\text { spp }\end{array}$ & $\begin{array}{l}\text { Prevotella } \\
\text { spp }\end{array}$ & $\begin{array}{l}\text { Porphyro- } \\
\text { monas } \\
s p p\end{array}$ & B fragilis & Total \\
\hline Abscesses & 52 & 26 & 1 & 2 & 2 & 7 & 2 & 4 & & 7 & 7 & 5 & 17 & 80 \\
\hline Blood & 3 & 1 & & & & & & & & & & & 2 & 3 \\
\hline \multicolumn{15}{|l|}{$\begin{array}{l}\text { Pulmonary } \\
\text { Aspiration }\end{array}$} \\
\hline Empyema & 5 & 3 & & & & & & & & 2 & 3 & 1 & $\frac{2}{1}$ & $\begin{array}{l}41 \\
10\end{array}$ \\
\hline Tracheostomy assoc & 10 & 10 & 1 & & 1 & & 1 & 2 & & 6 & 13 & 4 & 2 & 40 \\
\hline $\begin{array}{l}\text { Ventilator } \\
\text { pneumonia }\end{array}$ & 4 & 2 & & & 1 & & 1 & 2 & & 4 & 2 & 1 & 1 & 14 \\
\hline $\begin{array}{l}\text { Wounds } \\
\text { Post-traumatic }\end{array}$ & 7 & 5 & & & & 3 & 1 & & 1 & & 3 & 1 & 2 & 16 \\
\hline Cellulitis & 10 & 4 & & 1 & & 6 & & & & & 1 & & $\frac{2}{2}$ & 14 \\
\hline Tracheostomy & 3 & 3 & 1 & & & & & 2 & & 2 & 5 & 1 & & 14 \\
\hline Fasciitis & 2 & 2 & & & & & & & & & 2 & & 1 & 5 \\
\hline Gastrostomy & 4 & 3 & & & & 1 & & & & & 2 & 1 & 2 & 9 \\
\hline Myositis & 5 & 4 & & & & 2 & & & & 1 & 1 & & 3 & 11 \\
\hline Decubitus ulcer & 5 & 3 & & & & & & & & 1 & 2 & & 3 & 9 \\
\hline Bites & 42 & 30 & 3 & & & & 3 & 3 & & 17 & 15 & 2 & & 73 \\
\hline Peritonitis & 4 & 2 & & & & 1 & & 1 & & & & & 4 & 8 \\
\hline Osteomyelitis & 5 & 4 & & & & 1 & & & & 2 & 2 & & & 9 \\
\hline Sinusitis & 3 & 1 & & & & & & 1 & & 2 & 3 & & & 7 \\
\hline Total & 175 & 115 & 8 & 3 & 6 & 21 & 9 & 16 & 2 & 52 & 68 & 21 & 42 & 363 \\
\hline
\end{tabular}


Table 2 Aerobic and facultative bacteria isolated from 175 specimens obtained from 166 children with post-trauma infection

\begin{tabular}{|c|c|c|c|c|c|c|c|c|c|c|c|c|c|c|c|c|c|}
\hline & $\begin{array}{l}\text { a Haem } \\
\text { strep }\end{array}$ & $\begin{array}{l}\text { Str } \\
\text { pneum }\end{array}$ & $\begin{array}{l}\text { Str } \\
\text { pyog }\end{array}$ & $\begin{array}{l}\text { Group } \\
\text { D strep }\end{array}$ & $\begin{array}{l}\text { Staph } \\
\text { aureus }\end{array}$ & $\begin{array}{l}\text { Staph } \\
\text { epiderm }\end{array}$ & $\begin{array}{l}H \\
f l u\end{array}$ & E coli & $\begin{array}{l}\text { Kl } \\
\text { pneum }\end{array}$ & $\operatorname{Pr} s p$ & $\begin{array}{l}\text { Ps } \\
\text { aerug }\end{array}$ & Ent $s p$ & $\begin{array}{l}\text { Eikenella } \\
\text { corrodens }\end{array}$ & $\begin{array}{l}\text { Past } \\
\text { multocida }\end{array}$ & $\begin{array}{l}\text { Ser } \\
\text { marc }\end{array}$ & $\begin{array}{l}\text { Citro- } \\
\text { bacter sp }\end{array}$ & Total \\
\hline Abscesses & 3 & 5 & & 3 & 16 & 1 & & 7 & 1 & 2 & & & & & & & 38 \\
\hline Blood & & & & & & & & 1 & & & & & & & & & 1 \\
\hline $\begin{array}{l}\text { Pulmonary } \\
\text { Aspiration } \\
\text { pneumonia }\end{array}$ & 3 & & & 2 & 2 & & & & 3 & & 4 & & & & 1 & 1 & 16 \\
\hline Empyema & & 1 & & & 2 & & & & 1 & 1 & & & & & & & 5 \\
\hline Tracheostomy assoc & & & & & 3 & & & & & 1 & 3 & 2 & & & 1 & & 10 \\
\hline $\begin{array}{l}\text { Ventilator } \\
\text { pneumonia }\end{array}$ & 1 & & & & & & 1 & & 1 & & 1 & & & & & & 4 \\
\hline Wounds & & & & & & & & & & & & & & & & & \\
\hline $\begin{array}{l}\text { Post-traumatic } \\
\text { Cellulitis }\end{array}$ & 1 & & $\frac{1}{2}$ & & $\frac{2}{4}$ & 1 & & & 2 & & 1 & 1 & & & & & $\frac{6}{9}$ \\
\hline Tracheostomy & 1 & & & & 1 & & & & & & 1 & & & & & & 3 \\
\hline Fasciitis & & & 1 & & 1 & & & & & & & & & & & & 2 \\
\hline Gastrostomy & & & & 2 & & & & 2 & & & & & & & 1 & & 5 \\
\hline Myositis & & & 1 & & & & & & & & & & & & & & 1 \\
\hline Decubitus ulcer & & & & & 2 & & & 1 & & & & & & & & & 3 \\
\hline Bites & 7 & & 5 & 2 & 16 & 5 & 1 & & 1 & & & & 4 & 6 & & & 47 \\
\hline Peritonitis & & & & 1 & & & & 2 & & & & & & & & & 3 \\
\hline Osteomyelitis & & & 1 & & 1 & & & & & & & & & & & & 2 \\
\hline Sinusitis & & & & & 1 & & & & & & 2 & & & & & & 3 \\
\hline Total & 16 & 6 & 11 & 10 & 51 & 7 & 2 & 13 & 9 & 4 & 12 & 3 & 4 & 6 & 3 & 1 & 158 \\
\hline
\end{tabular}

aerug, aeruginosa; Ent, enterobacter; epiderm, epidermidis; Haem, haemolytic; $\mathrm{H}$ flu, Haemophilus influenzae; pneum, pneumoniae; Pr, proteus; Ps, pseudomonas; pyog, pyogenes; Ser, serratia.

procedures and devices used in the hospital during prolonged admission, and because of impaired cellular and humoral immune responses. ${ }^{2}$ Most previous reports of infection after trauma in children have highlighted the importance of aerobic or facultative organisms. These included Staph aureus, Str pyogenes, enterobacteriaceae, and Ps aeruginosa. ${ }^{2}$ Even though Clostridium spp were recovered from infections after trauma mostly associated with exposure to soil, ${ }^{3}$ the role of other anaerobic bacteria in trauma associated infections was not systematically reported.

This retrospective review summarises my experience in the past 20 years in the recovery of aerobic and anaerobic bacteria from infections after trauma in children. Some of the data have been published before in papers describing the role of anaerobic bacteria in various paediatric infections, ${ }^{4}$ but I also include cases not previously presented, and outline the spectrum of anaerobic infections after trauma in children.

\section{Methods}

PATIENTS

The specimens included in this review were studied or reviewed by me between June 1974 and June 1994. I include in my analysis only specimens that were studied for both aerobic and anaerobic bacteria. They were collected in the following hospitals: University of California Medical Center, County Medical Center, and Serra Memorial Hospital in Los Angeles, and Fairview State Hospital, Costa Mesa, California; Children's Hospital National Medical Center and South-East Community Medical Center in Washington, DC; and the Naval Hospital in Bethesda, Maryland.

Records of the clinical microbiology laboratories were reviewed to identify post-traumatic patients with anaerobic infections. The available case histories of all patients from whom these organisms had been isolated were reviewed to ascertain the presence and site of infection, associated microorganisms, underly- ing disease processes, and possible predisposing or associated conditions. Eighteen patients whose case notes were not available for review were not included in the final analysis.

\section{MICROBIOLOGY}

Only specimens that were properly collected without contamination by the normal skin or mucus surface flora and submitted in transport media appropriate for anaerobic bacteria were accepted by the microbiology laboratories. These specimens were generally obtained by aseptic needle or biopsy aspiration of abscesses or fluid from body cavities. Lung aspirates were obtained by transtracheal aspiration, through the tracheostomy or ventilator tubing, or by biopsy. When possible, pus and fluids were collected and transported in syringes. Tissues were transported in oxygen-free gassed-out tubes. Swab specimens were submitted in the Port-A-Cul transport swab system (BBL Microbiology Systems, Cockeysville, Maryland, USA). However, precise records of all of the transport media used were not always available.

Sheep blood (5\%), chocolate, and MacConkey agar plates were inoculated for the isolation of aerobic organisms. The plates were incubated at $37^{\circ} \mathrm{C}$ aerobically (MacConkey agar) and under $5 \%$ carbon dioxide (blood and chocolate agar) and examined at 24 and 48 hours. For the isolation of anaerobes, specimens were plated onto prereduced vitamin $\mathrm{K} 1$ enriched Brucella blood agar, anaerobic blood agar plates containing kanamycin and vancomycin, and anaerobic blood plates containing colistin and nalidixic acid, and then inoculated into enriched thioglycolate broth. The plated media were incubated in GasPak jars (BBL Microbiology Systems) and examined at 48, 96 , and 120 hours. The thioglycolate broth was incubated for 14 days. Anaerobes and aerobic bacteria were identified by techniques previously described..$^{56}$ 
Table 3 Bacteria isolated from 52 abscesses associated with trauma in children

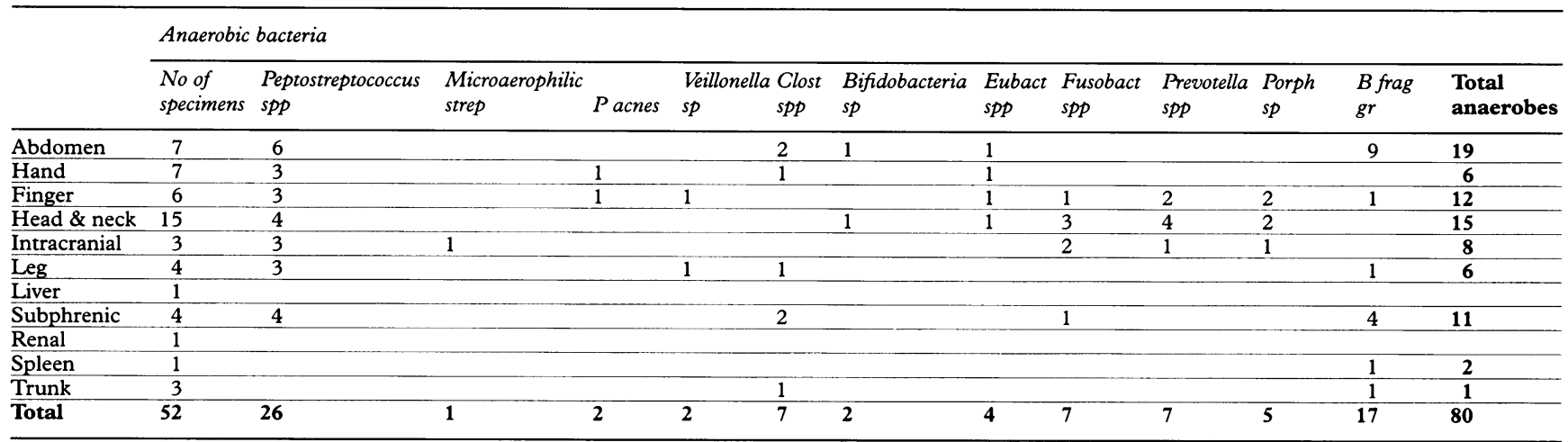

Clost, clostridium; epid, epidermidis; Eubact, eubacteria; frag, fragilis; fusobact, fusobacterium; haem, haemolytic; Kl pneum, Klebsiella pneumoniae; Porph, porphyromonas.

\section{Results}

PATIENTS

During the study period, bacterial growth was detected in 175 specimens obtained from 166 patients who sustained trauma (tables 1 and $2)$. The trauma included blunt trauma (71), lacerations and penetrating trauma (53), and bites (42). Patients' ages ranged from 13 months to 18 years (average 12.6 years); there were 128 males and 38 females.

Predisposing or underlying conditions other than trauma were noted in 86 cases (52\%). A single condition was present in 43 cases, two such conditions were recorded in 25 , and three in 18. These conditions were: the presence of a foreign body (for example, catheter, tube) in 64 (39\% of all patients); previous surgery in 40 (24\%), steroid treatment in $17(10 \%)$, neurological deficiency in $14(8 \%)$, malignancy in five $(3 \%)$, diabetes in four $(2 \%)$, and sickle cell disease in three $(2 \%)$.

\section{ORGANISMS}

Anaerobic bacteria only were isolated in 38 specimens $(22 \%)$, aerobic or facultative only in $51(29 \%)$, and mixed aerobic-anaerobic flora in $86(49 \%)$.

In all, 363 anaerobic isolates (2.1/specimen) (table 1) and 158 aerobic or facultative isolates (0.9/specimen) (table 2 ) were recovered. A single isolate was recovered in 81 specimens $(46 \%)$. The number of isolates in instances of polymicrobial infections varied between two and seven. No consistent pattern of combinations was noted.

The anaerobic bacteria included Peptostreptococcus spp. (115, which included 30 Peptostreptococcus asaccharolyticus, 18 Peptostreptococcus magnus; 15 Peptostreptococcus prevotii; 14 Peptostreptococcus micros, 14 Peptostreptococcus anaerobius, and three Peptostreptococcus morbilorium); Prevotella spp. (68, which included 18 Prevotella melaninogenica, 14 Prevotella intermedia, 13 Prevotella oralis, five Prevotella orisbuccae, and three Prevotella bivia); Fusobacterium spp. (52, which included 31 Fusobacterium nucleatum, six Fusobacterium necrophorum, and two Fusobacterium varium); Bacteroides fragilis group (42, which included $27 B$ fragilis; six $B$ thetaiotaomicron, four $B$ vulgatus, two $B$ distasonis, two $B$ ovatus, and one $B$ uniformis), 21 Porphyromonas asaccharolytica, and 21 Clostridi- um spp (including 10 Clostridium perfringens, two Clostridium ramosum, and one Clostridium innocuum).

The predominant aerobic or facultative organisms isolated (table 2) were: Staph aureus (51 isolates), $\alpha$ haemolytic streptococci (16), $E$ coli (13), Ps aeruginosa (12), Str pyogenes (11), group D streptococci (10), Klebsiella pneumoniae (9), and Staph epidermidis (7). No correlation was found between the recovery of different organisms and the clinical outcome and complications or length of stay.

\section{TYPES OF INFECTIONS}

Abscesses

The abscess developed following a variety of types of trauma, and were noted eight to 22 days after the initial injury. The abdominal abscesses emerged following either crush (four cases) or penetrating trauma (three cases), all after the development of peritonitis. The hand, finger, leg, and trunk abscesses followed laceration (11), crush (4), or penetrating trauma (2). The head and neck abscesses occurred after penetrating (6), laceration (5), or crush injuries (3). The liver, renal, and splenic abscesses followed abdominal crush injuries. All the intracranial abscesses followed cranial trauma, in one case associated with basilar skull fracture, and in another with cerebrospinal fluid leakage into the nasal cavity.

In the 52 patients with abscesses (table 3), the most common were of the head and neck (15), hand (7), abdomen (7), and finger (6). The most common organisms were Peptostreptococcus spp (26 isolates), B fragilis group (17), Staph aureus (16), and Clostridium spp, Fusobacterium spp, Prevotella spp, and $E$ coli (7 each). $B$ fragilis, $E$ coli, and group D streptococci predominated in abdominal and subphrenic abscesses, Prevotella, Porphyromonas, and Fusobacterium spp were prevalent in finger, head and neck, and intracranial abscesses, and Staph aureus and Str pyogenes were commonly isolated in hand, finger, and head and neck abscesses.

\section{Bacteraemia}

Three patients had bacteraemia associated with trauma. Two with abdominal trauma had $B$ fragilis group isolates; one in a patient with abdominal abscess was recovered as a single isolate, and the other (a $B$ thetaiotaomicron) was 
Table 3 continued

\begin{tabular}{|c|c|c|c|c|c|c|c|c|}
\hline \multicolumn{9}{|c|}{ Aerobic bacteria } \\
\hline $\begin{array}{r}\text { a haem } \\
\text { strep }\end{array}$ & $\begin{array}{l}\text { Strep } \\
\text { pyog }\end{array}$ & $\begin{array}{l}\text { Group D } \\
\text { strep }\end{array}$ & $S$ aureus & $S_{\text {epid }}$ & E coli & $\begin{array}{l}\text { Kl } \\
\text { pneum }\end{array}$ & $\begin{array}{l}\text { Proteus } \\
s p\end{array}$ & $\begin{array}{l}\text { Total } \\
\text { aerobes }\end{array}$ \\
\hline & & 2 & & & 5 & & 1 & 8 \\
\hline & 2 & & 3 & & & & & 5 \\
\hline 2 & & & 3 & & & & & 5 \\
\hline 1 & 2 & & 5 & 1 & & 1 & & 10 \\
\hline & 1 & & & & & & & 1 \\
\hline & & & 1 & & & & & 1 \\
\hline & & & 1 & & & & & 1 \\
\hline & & 1 & & & & & 1 & 2 \\
\hline & & & & & 1 & & & 1 \\
\hline & & & & & 1 & & & 1 \\
\hline & & & 3 & & & & & 3 \\
\hline 3 & 5 & 3 & 16 & 1 & 7 & 1 & 2 & 38 \\
\hline
\end{tabular}

recovered with $E$ coli. Peptostreptococcus magnus was isolated from a patient with fasciitis. A similar organism was recovered from the skin lesion.

Pulmonary infections

Of the 30 patients with pulmonary infection, 11 had aspiration pneumonia, 10 had tracheostomy associated pneumonia, five had empyema, and four had ventilator associated pneumonia. An associated empyema was present in two of the patients with aspiration pneumonia, and similar organisms were isolated in both sites. The pulmonary infections developed eight to 33 days after the trauma. The organisms that predominated in all these infections were Peptostreptococcus, Prevotella, Porphyromonas and Fusobacterium spp, B fragilis group, Ps aeruginosa, and Staph aureus.

\section{Wounds}

Of the 36 patients with wounds, 10 had cellulitis following superficial skin injury, seven had post-traumatic lacerations, five had decubitus ulcer that emerged 15 to 41 days after the trauma, five had myositis, four had gastrostomy site infection following gastrostomy tube placement, three had tracheostomy site wound, and two had fasciitis. The organisms predominating in these sites were Prevotella spp, $B$ fragilis group, Clostridium spp, Staph aureus, and Str pyogenes. Group D streptococci, $E$ coli, and Serratia marcescens were only isolated from gastrostomy site wounds. Most infections involving anaerobic bacteria were polymicrobial.

\section{Bites}

Forty two patients sustained bites: 23 animal and 19 human. The predominant isolates in all bites were Peptostreptococcus, Fusobacterium and Prevotella spp, and Staph aureus. All Pasteurella multocida and three of the four Eikenella corrodens were recovered only from animal bites.

\section{Peritonitis}

All of the four patients with peritonitis had abdominal trauma-penetrating in two, crush injury in two. One of these patients also developed an abdominal abscess. In these four patients, $B$ fragilis and $E$ coli were the predominant isolates.

\section{Osteomyelitis}

One patient had facial injury that involved the maxillary sinus. Fusobacterium spp and Peptostreptococcus spp were isolated from this patient. Another patient had trauma of the femur, where $C$ perfringens was recovered. Three patients who sustained bites had osteomyelitis of the metacarpal bone (two human bites and one dog bite). The patients with human bites who developed osteomyelitis had Peptostreptococcus spp, Prevotella spp, E corrodens, and Str pyogenes. The dog bite infection had Staph aureus, Fusobacterium nucleatum, and Peptostreptococcus spp.

\section{Sinusitis}

The three infections associated with sinusitis were of the maxillary sinus and following extensive use of gastric and nasal tubes. Prevotella and Fusobacterium spp and Ps aeruginosa were the predominant organisms.

\section{TREATMENT AND OUTCOME}

Antimicrobial treatment was given to all patients, and surgical drainage or correction of pathology in $71(43 \%)$. The antimicrobial agents given were an aminoglycoside in 93, clindamycin in 46 , a penicillin in 33 , a cephalosporin in 30 , erythromycin in 18 , metronidazole in 17 , and chloramphenicol in nine.

Two of the patients died of their infection, one with peritonitis and the other with aspiration pneumonia.

\section{Discussion}

This retrospective review shows the polymicrobial nature of many infections that follow trauma. The source of these infections can be exogenous or endogenous. Exogenous pathogens in wounds generally originate from the environment where the injury occurred. Clostridium spp are associated with soil, Aeromonas hydrophilia and Vibrio fulnificus with water, and Staph aureus with fomites. Exogenous organisms are also derived from the normal flora of the skin, or the frequent colonisation of the mucous membranes by Staph aureus or Str pyogenes at or adjacent to the site of injury. Endogenous bacteria are derived from the polymicrobic flora of the oropharynx, gastrointestinal tract, and vagina, where anaerobic bacteria outnumber facultative organisms in ratio of 100 or 1000 to 1 , depending on the location. ${ }^{7}$ Knowledge of the normal microbial flora at the site of the trauma can assist in the selection of antimicrobial prophylaxis and empirical antimicrobial treatment.

Staphylococci and aerobic and anaerobic streptococci colonise the skin. These organisms were recovered from all sites in our patients. Potential pathogens from oropharyngeal flora include streptococci, Prevotella, Porphyromonas, Fusobacterium, and Peptostreptococcus spp. These organisms were isolated from infections that originated from these sites and included pulmonary infections, head and neck wounds and abscesses, and bites. The gastrointestinal tract and vaginal flora include enterobacteriaceae, Enterococcus spp, and anaerobic bacteria such as the $B$ fragilis group and 
Clostridium and Peptostreptococcus spp. ${ }^{7}$ These organisms were recovered in peritonitis, abdominal abscesses, decubitus ulcers, and wounds of the lower extremities. A similar distribution of organisms were also observed in such infections in children without trauma. ${ }^{4}$

The importance of anaerobic bacteria was highlighted in this study in endogenous infections adjacent to sites where anaerobic bacteria are part of the normal flora. These sites included the oral cavity, which was the origin of organisms that predominated in the head and neck and in pulmonary infections, and the gastrointestinal flora, which predominated in abdominal and lower extremity infections.

The high risk for infection after trauma is related to several factors: occurrence of poor perfusion or shock, the viability of tissue following necrosis or haemorrhage, the number and virulence of organisms, host resistance, adequacy of surgical debridement, and underlying conditions. ${ }^{1}$ Interruption in the integrity of the skin and mucosal surfaces leads to contamination of tissue by organisms from the environment or by normal flora. Presence of foreign debris such as wood splinters or glass fragments, or of medically installed devices such as catheters, tubes, surgical drains, and vascular prosthetic devices, allows pathogens to circumvent skin and mucosal barriers and persist on these foreign surfaces. The presence of haematoma or accumulation of serum, and devitalisation or ischaemia of injured tissue, provides a favourable environment for growth of pathogens, including anaerobic bacteria, with decreased access of immune responses.

Traumatic wounds are immediately contaminated to variable degrees at the time of injury. Highly contaminated wounds should not be closed primarily. Early thorough irrigation of the wound can reduce the number of organisms and remove debris and foreign bodies. Exogenous bacteria causing infections depend on the circumstances of the trauma and contamination. Endogenous bacteria contaminate wounds adjacent to their usual sites of colonisation: oral flora can contaminate head and neck injuries, while gut and vaginal flora can infect lower body wounds. Various species of staphylococci and streptococci can be recovered from all cutaneous body sites. Synergistic gangrenous infections are especially associated with crush injuriesclostridial myonecrosis and necrotising fasciitis are examples. ${ }^{89}$

Deep penetrating wounds can contaminate the underlying muscle, causing pyomyositis. The risk of pyomyositis is especially high when a foreign body is involved. The predominant organisms depend on the body site and circumstances of injury. These are Staph aureus, streptococci, Peptostreptococcus spp, B fragilis group, and Clostridium spp. ${ }^{10}$

Skin flora or environmental organisms can enter the soft tissue and increase the potential of infection if the skin overlying a fracture is lacerated. Post-traumatic chronic osteomyelitis with and without union can occur after compound fractures. Organisms that predominate in these infections are staphylococci, enterobacteriaceae,

Ps aeruginosa

and

Clostridium spp. ${ }^{11}$

Abdominal penetration or blunt trauma often leads to infection. Spillage of the bacterial contents of the gastrointestinal tract can lead to acute peritonitis which is often associated with septicaemia or delayed abscess formation, or both. Organisms responsible for acute peritonitis are mostly enterobacteriaceae, while abscesses are polymicrobial, caused by enterobacteriaceae and the $B$ fragilis group predominately. ${ }^{12}$

Nosocomial pneumonia is a major cause of morbidity and mortality after trauma. Unconscious and intubated patients are at higher risk because of aspiration pneumonia. Infection can progress to lung abscess and empyema. Organisms recovered from these infections are aerobic and anaerobic members of the oral flora, enterobacteriaceae, Ps aeruginosa, and Staph aureus. ${ }^{13}$

Head trauma causing cerebrospinal leak can lead to meningitis, ventriculitis, and brain abscess. The risk of infection is highest when there is basilar skull fracture and if there is not prompt, adequate care of the wound. ${ }^{14}$ Posttraumatic cerebral oedema can preclude performing a diagnostic lumbar puncture. Streptococcus pneumoniae, Staph aureus, and facultative Gram negative bacilli are the most common aetiological agents.

General principles of prevention of infection following severe trauma include aggressive intensive care to maintain blood volume and to support respiratory function and nutrition. Prompt drainage of collections of fluid, evacuation of haematomata, debridement of devitalised tissues, and suctioning of respiratory secretions optimises outcome. Prompt infection control measures, such as hand washing, wearing gloves, and so on, can reduce nosocomial spread of potential pathogens and the risk of infection by resistant bacteria.

Prophylactic antibiotics should not be given to patients with clean and uncontaminated injuries. Unnecessary or prolonged antimicrobial treatment increases the risk of infection with resistant bacteria, and has adverse effects and costs. Antimicrobial prophylaxis, when adequately given, can reduce the rate of certain post-traumatic infections. Prophylaxis is given for heavily contaminated skin wounds, or when a large amount of soft tissue injury is present. Generally, a first generation cephalosporin (cefazolin) is adequate. In wounds associated with farm accidents, penicillin $G$ should be given for prophylaxis against Clostridium spp. Antimicrobial prophylaxis, generally against staphylococci, should also be given to patients with open fractures. ${ }^{11}$ This is especially important when high contamination from the environment or mucous membranes is suspected, and in facial fractures. If the sinus wall was violated, or sinusitis is present, an agent such as cefuroxime provides a broader spectrum of activity against likely organisms.

Preoperative antimicrobial agents have been used successfully in patients with abdominal trauma and suspected ruptured viscus. ${ }^{11} 15$ Treatment is directed at predominant gastroin- 
testinal flora (that is, the $B$ fragilis group and enterobacteriaceae). Regimen used is either a single broad spectrum agent (for example, cefoxitin, an extended spectrum penicillin plus a $\beta$-lactamase inhibitor, or a carbapenem), or a combination of agents (for example, clindamycin or metronidazole plus an aminoglycoside, quinolone, or third generation cephalosporin).

I acknowledge the efforts of the clinical and laboratory staffs a the participating hospitals and the secretarial assistance of Joanie Pietrafitta.

1 Caplan ES, Hoyt N. Infection surveillance and control in the severely traumatized patient. In: Dixon J, ed. Nosocomial infections. New York: Yorke Medical Books, 1982:24751.

2 Bjornson HS. Therapy and prevention of infections in the trauma patients. Proc Crit Care Med 1984;1:231-47.

3 Nichols RL, Smith JW. Gas in the wound: what does it mean? Surg Clin North Am 1975;55:1289-96.

4 Brook I. Pediatric anaerobic infections: diagnosis and management, 2nd ed. St Louis: CV Mosby, 1989.
5 Summanen P, Baron EJ, Citron DM, Strong CA, Wexler HM, Finegold SM. Wadsworth anaerobic bacteriology manual, 5th ed. Belmont, CA: Star Publishing, 1995.

6 Murray PR, Baron EJ, Pfaller MA, Trenover PC, Yolken RH. Manual of clinical microbiology, 5th ed. Washington, DC: American Society for Microbiology, 1993.

7 Rosebury T. Microorganisms indigenous to man. New York: McGraw-Hill, 1962.

8 Wang KC, Shih $\mathrm{CH}$. Necrotizing fasciitis of the extremities. J Trauma 1992;32:179-82.

9 Brook I, Frazier EH. Clinical and microbiological features of necrotizing fasciitis. J Clin Microbiol 1995;33:2382-7.

10 Renwick SE, Ritterbusch JF. Pyomyositis in children. J Pediatr Orthop 1993;13:769-72.

11 Patchen ED. Antibiotic prophylaxis in trauma: penetratin abdominal injuries and open fractures. Rev Infect Dis 1991;13:S847-57.

12 Brook I. Bacterial studies of peritoneal cavity and postoperative surgical wound drainage following perforated appendix in children. Ann Surg 1980;192:208-12.

13 Brook I, Finegold SM. Bacteriology of aspiration pneumonia in children. Pediatrics 1980;65:1115-20.

14 Appelbaum E. Meningitis following trauma to the head and face. JAMA 1969;173:1818-22.

15 Brook I. Management of infection following intraabdominal trauma. Ann Emerg Med 1988;17:626-32.

\section{Hong Kong Academy of Medicine First International Congress, Hong Kong,}

\section{6-29 November 1998}

\section{Challenges to Specialists in the 21st Century}

Plenary lectures: Challenges to the specialist beyond 2000; Evidence based medicine; Survival of the generalist in a specialist world; The quest for transplantation tolerance; The training of our specialists into the next millennium; Pain-free state: is it possible?

The scientific programme includes symposia on trauma, pain management, and substance abuse.

Deadline for abstracts: 31 May

Further information from: Congress Secretariat, Hong Kong Academy of Medicine, First International Congress, GPO Box 41, Hong Kong; tel (852) 2515 5737; fax (852) 2505 3149; email: hkam@hkam.org.hk 